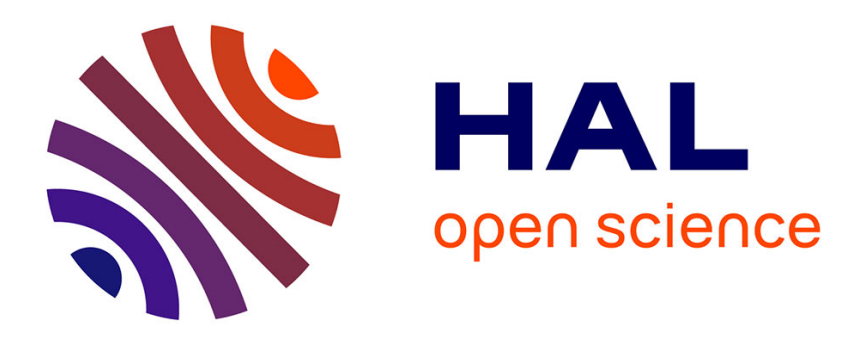

\title{
Settlement systems in the evolution
}

Denise Pumain

\section{- To cite this version:}

Denise Pumain. Settlement systems in the evolution. Geografiska Annaler, 2000, 82B (2), pp.73-87. halshs-01565293

\section{HAL Id: halshs-01565293 \\ https://shs.hal.science/halshs-01565293}

Submitted on 19 Jul 2017

HAL is a multi-disciplinary open access archive for the deposit and dissemination of scientific research documents, whether they are published or not. The documents may come from teaching and research institutions in France or abroad, or from public or private research centers.
L'archive ouverte pluridisciplinaire HAL, est destinée au dépôt et à la diffusion de documents scientifiques de niveau recherche, publiés ou non, émanant des établissements d'enseignement et de recherche français ou étrangers, des laboratoires publics ou privés. 


\section{SETTLEMENT SYSTEMS IN THE EVOLUTION}

by

Denise Pumain

Pumain, Denise, 2000: Settlement systems in the evolution

The authors of a recent bibliographical essay $(\mathrm{Pu}-$ main and Robic, 1996) stressed the degree to which theoretical approaches to urban places are static. When such theories do include time, it is usually only implicitly. The focus of explanatio tends to be on structures, and much more rarely o the forms taken by change. No theory of urba systems, especially those expressed in geometrical or mathematical models, has so far satisfactorily integrated the urban phenomenon's temporat dimension, in the sense of change over historical time. However effective static interpretations may appear, as explanatory tools they completely overlok what is an essential characteristic of town and cities, namely their capacity to chenge and adapt over time. The basic question to be addressed is that of how and why the man in the treet is not mistaken to go on describing as "town" or "city" objects whose form, content as

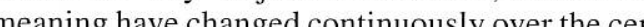
wies.

It is important to be clear that an evolutionary im is not to consider the whole sweep of . The history, nor to reconstruct the particep of urban f urban genesis. The approp is not that of hisorical stury in the sense of explong the past

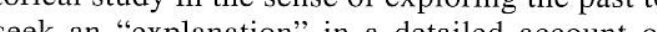

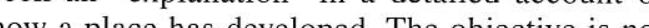
he a plipe on 列 ustead that of producing a theoretical formalization of urban evolution as the process of the historical transformation or specific settlements. The aim is to demonstrate that a geographical object can be interpreted as the particular outcome, from among a set of possible outcomes, of a general dy namic process. In making the simplifications necessary for modelling, the notions of uniquenes and unrepeatability that characterise historical objects are inevitably lost, but it does take into account the non-reversibility of their particular history.

Geografiska Annaler · 82 B (2000) $\cdot 2$

\section{Difficulties in static explanations}

As their structure is evolving slowly, it is not surprising that explanations for settlement systems been initially searched in static ainly in the framework of economics. But systems could be adequed fiom the principles of general conomis theory Economic theory is missing both the spatial and evolutionary features which seem indippensable for a real understanding of urban systems.

Agglomeration economies and central places

Most urban theorists who have based their work on micro-economic theory explain the spatial clustering of economic agents, assumed to be utility maximisers, by the existence of "agglomeration econies" or "economies of scale external to the firm" (Catin, 1994, p. 105). An initial difficulty with thi at although these "agglomeration economies" are frequently invoked they are never actually measured. It can also be pointed out that for decitions about localisation to be based on agglomeration economies assumes that the town or city alhow it deve and heor how it developed. Another criticism that can be that the town or city exists in isoling assume that the town or city exists in isolation: the agents cluster according to their individual interests without there being any necessary relations with other urban places. In order to explain urban systems an to account for their hierarchical structure, the micro-economic theories make the assumption that returns increase with he size of urban centre. Fo example, Fujita et al. (1994) work on the hypothesis that the system optimises its operation by establishing an equilibrium between supply and deman for services at the meso-scopic level of the city, while individuals optimise their localisation by maximising their utility. This means that the town and cities which offer the widest range of service will be more attractive, and the influx of migrants will in turn cause an increase in the range of serv- 
ices they can offer. Large cities are thus more attractive and grow faster than smaller ones, but the theory does not explain why differences in city size ticular form or why this is stable over time.

Central place theory, in its original formulation, is a static theory and it takes for aranted the structure it purports to explain According to this theory. postulating the existence of different levels of poods and services (organised according to how mooch they are in (omand, which determines the different ranes and thresholds of appearance) is different ranges and the existence of hierarchice the basis for dicing the existence of hierarchica

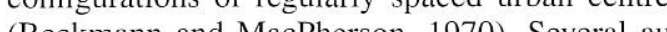
(Becks, in thors, including H. Beguin $(1979,1988)$ have introduced stochastic elent stepped hierarchy or the models closer to the linearity actually observed in urban settlment sizes. However, ho satisfactory explanation has been given of how the link is established between the hierarchy of the differentgoods and services and the hierarchy of the central places. The concentration of goods of the same order in each central place is postulated but is not demonstrated by the theory, nor does the theory indicate how the urban hierarchy thus formed is likely to evolve. Christaller's book (1933) includes a chapter of suggestions on thi subject, but they are not incorporated into his mod-
els, which thus remain structural and static.

Static and equilibrium theories

Urban theories that give a static interpretation are unconvincing because they apply on the level of individuals, that is, the agents whose behaviour is formalised in the models, processes which they assume to be universally valid regardless of time an place. They completely disregard the historical nature of the urban object and can thus be said to contradict themselves in that they use the mechanisms of today to try to explain an entity that has been produced over time. If a city were to be built today from scratch applying the principles of these theories, it is doubtful that it would resemble any known city in either its unique character or its principle of functioning. The present form is the result of a long evolution and cannot correspond to the optimisation of a handful of factors at a particular point in time. The mechanisms developed in micro-economic analysis to explain the concentration of the agents and agglomeration economies make no allowance for the length of time their action requires.

The problem is that behind all the static explanations for the size and spatial arrangement of urban settlements can be discerned the notion of equilibrium, governed by a determining factor in the form of some force, an "invisible hand", a statistical constraint. The form of urban networks has thus been "explained" by the action of contradictory forces working for unification and diversification (Zipf, 1949), by the micro-economic theory of markets (whose centrality is the spatic theory of marthe (whose centrality is the spatial expression of che principle according to Berry (1967)), by a principle of maximising social interaction (Claval, is deduced from a mechrocess in which a structure ing a limCurry 1964). All these exple (entropy maximising, from, Cury, 1964). All hese expla which can be summed up this. the conflgutions observed at any given training factor, or se the expresion of an equilibstraining factor, or are the expression of an aculiti(1994) con con " (1994) consider as a "hatural rule" (sic) that "at any militin

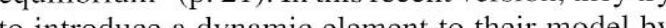
to introduce a dynamic element to their nodel by starting with a static equilibrium model and imagining the shifts in this point of equilibrium over time. Contrary to what is claimed by the authors, such a nodel does not allow to therstand 'the emergence of a system of cities

Long-term observation of the dynamics of urban networks does not supply proof that the dynamics of urban systems are governed by a macroscopic constraining factor, or that what is observed at any given time represents an equilibrium state. On the contrary, what we find are large or gradual changes in the distributions, but without knowing if the forces that are supposed to have produced them have changed. A certain dynamic can thus be identified at work within a geographical distribution. This dynamic is the product of interactions which, if they were allowed to operate unhindered over a long enough period, might result in an equilibrium tha could be modelled. In reality, of course, the form and intensity of the interactions have always changed before this equilibrium can be reached. Imagining that a system's current state corresponds to an equilibrium thus means assuming, if it is to be explained in these terms, a set of interactions which on their own cannot in fact explain the present form (Allen, 1991). We are thus forced to take the view that the configuration observed and the transformations it experiences must be explained by a single theory. With the same theory it must be possible to explain the structure of the system and the changes occurring in it.

The somewhat tautological hypothesis used by economists to justify the concentration of economic activities in urban centres, and which presupposic activies ince of est axper to me to be necessary to explain the differes in the size and evolution of towns and cities. An evolion ary theory can account for these without having to accept the idea that large cities without having to accept cive ide that large cities terms than small ones in order to explain the existterce deed, the greater economic efficiency of large urdeed, the greater econs in (Rousseu and Prudomme, 1993) and the case (Rousseat and Phum much the consequence as the cause of their success.

\section{Dynamic models of urban growth}

With the creation of historical and comparative data bases (Bairoch, 1996) a large volume of observations relating to change in urban systems is now available. Early efforts to incorporate this material into a theory involved the transfer of dynamic models from the 'pure' sciences of mathematics, statistics, physics and chemistry. However simplistic these models may be, they have a valuable filtering role. By making possible the comparison between urban dynamics and the dynamics of other systems they have helped to identify a number of specific aspects of urban evolution and thus contributed to the development of more sophisticated modelling.

Many models present merely a simplified description of urban systems in terms of sets of population centres characterised by their number of inhabitants. Although this simplification is extremely crude it is not meaningless given that 'demographic size is the variable which best expresses a wide range of functional properties of town and cities. Population size is a correlate for many quantitative descriptors, such as the number of jobs, firms or homes, but also for qualitative descriptors such as the diversity or complexity of economic activities and of urban society. It constitutes the main "dimension" of an urban system, its most important factor of differentiation. (Reine and Parr, 1980). Knowing the size of a city typically supplies a lot of other information about that city, and can thus be used to make a wide range of fairly accurate predictions. Size presents the addiional advantage of being measurable over very ong periods in a reasonably straightforward and stant significance in terms of the 'success' of the sub-system it represents. The fact of attracting and keeping a certin number of residents was for and taken as the measure of a city's capacity to provide the means of subsistence for this population through local production and innovation, but also by the extraction of surplus from the cout also or other ub centres, or by imposing countryside a sytem of exces. For posing its terms in (tions dicator of urbe success needs to be completed by dive put, as well a by inglicators of a dity of life unt put, as well as by

For the purposes of this article we will just use this description of the system in terms of city size or the formal part of the thery. This does not mean that an evolutionary theory has no further extension. It is merely a first stage, and it will in fact be seen that a coherent and formalised conceptualisaine leads to including far more complex aspects of he definition of an urban system even in this simplified version of the theory.

Gibrat's model

The simplest alternative to the static point of view is the approach which treats urban systems as the product of a stochastic process distributing population growth between cities. This involves transferring a statistical model for the dynamic description of an urban system. In his book. Les inégalités économiques (1931), Gibrat demonstrated that when cities are growing at the same average speed but with fluctuations or inequalities of growth, the distribution of the city sizes will consistently take a particular form.

Let there be a set of localities with a certain size distribution (they can even be all the same size at the start of the process) and whose evolution over a long period (several centuries, for example) is modelled, using a large number of short time periods. It is assumed that in each time period (for example, one year, or ten years) the population $\mathrm{P}_{\mathrm{i}}$ of each locality grows on average (though with fluctuations $\mathrm{e}_{\mathrm{i}}$ ) by an amount $\mathrm{dP}_{\mathrm{i}}$ which is proportional to the population $\mathrm{P}_{\mathrm{i}}$ (and low in relation to $\mathrm{P}_{\mathrm{i}}$ ):

$\mathrm{dP}_{\mathrm{i}}=\mathrm{rP}_{\mathrm{i}}+\mathrm{e}_{\mathrm{i}}$ 
This is the same as saying that the proportional rate of change of the population $\mathrm{dP}_{\mathrm{i}} / \mathrm{P}_{\mathrm{i}}$ (which is the measure usually expressed in percentage terms and used to describe and compare the growth of cities and regions) has the same average value for all settlements, whatever their size at the beginning of each time period. If in addition the distribution of these rates between localities is independent from one time period to the next, the growth process it defines will always result in a distribution of settlement sizes that is a lognormal distribution, highly skewed, characterised by a large number or villages and small towns and a geometric decline in the number of cities according to their size. If the rate of growth and its variations are known it is eve possible to predict (at a known probability) by how much the size disparity will increase.

With this process the attractiveness of cities does not have to be assumed to increase with their size in order to obtain a highly uneven size distribution, comprising a small number of very large cities (consequently there is no need for a theory like that of agglomeration economies). In addition, this model can be "tested" empirically against the statistical observations of urban growth rates at regular intervals over long periods. It has been confirmed for many different countries and period (Robson, 1973; Pumain, 1982; de Vries, 1984; Guérin-Pace, 1993; Moriconi-Ebrard, 1993). A more satisfactory "explanation" for the form of the distribution of city sizes is thus obtained when we view it as resulting from a dynamic process for the distribution of urban growth than simply as the expression of a static equilibrium. Compared with presse static interpretations, Gibrat's model is in fact the only one to show why this form of organistion is unchanging over time, and to deduce a red in ing large cities at the top of increasingly skewed distributions. The model thus provides an "expladistion" for the gradual differentiation in size bethe same evolu"in the with an uneven effect produced by the "an, hongh" (or random, in the sense that they are "accidental" (or by the model) repetition in some not determined by the model) tepetion in sore places of inct of challer than those expericrced by the set oibrat's cities. As a fist approxination, then, Gibrew model provides both a good deslaption of its hierin an tirban systen and exper archical structure. It can be used for predicting the evolution of decades.
However, a theory of urban systems cannot be the formulation of this purely stochastic model, especially if we want the theory to accon systematic deviations from Gibrat's model that are observed: first, over the long term there is usually a slight positive correlation beween urban growth rates and city size, second, they are sometimes temporally autocorrelated for periods of several decades (Robson, 1973; Pumain, 1982; Guérin-Pace, 1993). In addition, the "primate" cities, the two or three "metropolises" in the national urban hierarchies, whose size appears 'disproportionate' compared with the rest of the urban system, are in fact agglomerations which have grown systematically faster than the rest of the urban network over several decades (MoriconiEbrard, 1993; Pumain and Moriconi-Ebrard, 1997). The model therefore has to be corrected and completed so as to accommodate what in relation to the simple stochastic process appear as "anomalies" but which are in fact revealing of processe that are specific to the evolution of the urban system. This leads us to an explicit formalisation of the relations of interdependence between cities, an thus to a shift from a formalisation of a set of citie to that of a system of cities. In the Gibrat model, the notion of interdependence between cities remain implicit and is present only in the hypothesis that the growth rates of cities obey a distribution with the same average and with a given variance: the implication is thus that they belong to the same "system". This hypothesis does not appear as such in the statistical model and it is when the model is transferred to cities that it becomes logical to introduce it as expressing the information exchange and competition between cities.

Empirical observation also necessitates consideration of another process which is that of the se lection of those members of the set of inhabited localities which grow into towns and cities. The dynamics described by Gibrat in fact applies not only to urban places but more generally to the settlement system as a whole. Clearly, however, this dynamic tends to produce not one but two lognormal distributions, characterised by unequal degrees of contrast between the size of their elements. From our perspective, this implies that two subsets of localities have been subject to a long-term "selection", one for a dynamics of growth, the other for decline, as has been the case for the towns and rural communes in France over the last 200 years (Pumain 1995, p. 437). The distinction between towns and cities and villages thus leads to incorporating into the evolutionary theory qualitative considerations concerning the functions of settlement centres as well as the historical change known as the "urban well as the
transition".

\section{A dynamics of interdependence}

Communication, exchange and interdependence between similar entities are properties which appear to be linked to a geographical definition of the urban concept. For this reason the geographer finds it hard to accept the definition (presented as a "nondefinition”!) put forward by H. Beguin (1996), which emphasises the concept of density but does not satisfactorily articulate the two identifiable levels of urban organisation, the city and the city system, and above all fails to integrate the "ecological" dimension, that is, to provide an explanation of the urban object that is "vertical" rather than simply "spatial" or "horizontal". The individual urban place cannot be dissociated from the system of urban places, and exchange of whatever type or form, including therefore long-distance relations, are integral to the urban function and are part of its specificity. According to Henri Reymond (1981), what distinguishes the town and city from other forms of settlement (village, mining centre), which exploit purely local resources drawn from a single site, is the possibility of exploiting a situation, the resources of several different sites. This conception is consistent with the findings of historical and archaeological research regarding the genesis of towns and cities. For P. Bairoch, "the existence of an urban centre presupposes not only an agricultural surplus but also the means of exchanging this surplus" (1996, p. 19)

Reymond (personal communication, 1995) justifies his definition using the concept of limiting factor borrowed from ecology, which postulate that at any given moment the resources available to a population established in a particular location ac as a limit to its development: "The system of urban habitat is the basic ecological organism which, of all those invented by the human race, can eliminate the most completely the set of limiting factors of a site, whatever its own resources. Towns and cities have succeeded in overcoming the uncertainties arising from local limiting factors and in controlling these local difficulties, by developing multiple links and forming ever faster networks. Sites that are linked in this way can support a population much larger than was possible on the initial site. This evolution is not finished, and the tool that these towns and cities become is continually being inented".

The existence of a pattern in the evolution of interdependent urban centres was noticed long ago, for example by Reynaud (1841) when he introduced the concept of "general city system". Bery's (1964) famous phrase "cities as systems within systems of cities" was a use of systems theory as he framework in which to formalize the relationhip between the level of organization and obsevation formed by the city, viewed as a collection vig tou systemic relations, and the city system, organised on the principles of central place theory. In his

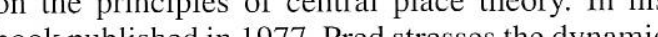
ar of the notion of urban system by defing inect of the notion of tenting it in ex ore in guch a way that an significant change in the stch a way that any significant change in the ecoconic activies, occupational structure, total income or population of one member city will directly or indirectly bing about some modification in ere al income, or pop nembers" (p. 13).

Subsequent empirical research on the ways in which urban systems evolve has demonstrated the value of interpreting their dynamics within the framework of self-organisation theory. This formalisation can be used to refine Pred's definition and in particular his notion of "significant change" Not all local transformations will affect the other cities in the system. Many of the changes that affect towns and cities over periods of several years or several decades (in urban morphology, in demographic, social and economic structures, etc.), though they could be described as 'significant', have no effect on the structure of the system, that is on the form of inter-urban differentiation, because they affect all towns and cities (Pumain and Saint Julien, 1978; Sanders, 1992). The structure of the system will also not be modified by changes that are particular to a town or city, because they do not last long enough from one period to the next and are mere fuctuations which do not alter the relative position of urban centres within the system. A structural change will occur when one of these fluctuations persists and increases to the point that it modifies this position, usually of several cities at the same time, related to the development of a new specialisation, for example. In this case there is said to be a bifurcation in the history of the system. Most fluctuations have no effect if they occur while the 
system is on a stable path (Pumain, 1997; Pumain et al., 1989). A bifurcation may also be the result of a perturbation originating outside the system in question.

Models based on self-organisation theories Observation of the ways in which interdependen cities evolve has prompted the transfer to geography of models originating in chemistry and physics. The analogy with physical systems, using the dissipative structures concept (Allen, 1978) or synergetics (Haken, 1977; Sanders, 1992), involve formalising the dynamics of systems as the product of interactions between microscopic units which together form structures that are detectable at the macroscopic level. The system thus described is "open": in the case of a physical system this mean that it receives an input of "energy" from the "exterior' which allows "self-organisation" to occur When the model is transferred to human systems, this energy input is assimilated to innovation, or to a trend towards growth of the system, which acts a the "motor" of its dynamics. Application of the self-organisation concept to these systems suggest that the fact that they are structured by a persisten and thus identifiable architecture cannot be explained by the action of a network operator or by any explicit political or economic objective, such as any explicitescribed in terms of some constraint to be respected or quantity to be optimised. The structure is in fact the spontaneous product of multiple inteis int ins between many separate agents. Each of these has its own objectives and strategies, but do not need to be known in detail in order to predict (or simulate) what will be the system's general archithe mass of individual decisions cectire. In this way the cancerion at equations whic les this is in principle possible usa macroscopic listic mode ing the probabilstic thery in which a "master and self-organisatios the overall effect of the interequation" expresses the overall efrectos whose inactions occuning betwin within the system candividual state and position withe the systen cannot be known (or predicted). The notion of rands event is thus linked to the existence of of observation in the system. the nicroscopic phenomena influence the form of the macrosepic phenomenon, while it is the latter's law which unifies the microscopic phenomena, or, ". The pords, subjects them to its "point of view". The particular laws of these two types of phenomena are not usually random laws, and these are merely the laws of

Self-organising systems are not in a state of

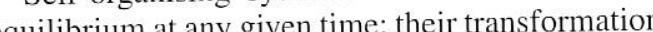
is the ricult of iny gin is the result or internal and is the product of this evesses, and their structure is the product on ths evolution. Change in urban centres or urban systems takes forms similar to those in the physical theories of self-organisation. This combines, on the one hand, a stability or slow transformation in the system's structure (the macro-geographical state of the urban system as reflected the form of the size distribution, the main differentiating factors in the economic activities and social composition of cities), and on the other, very large fluctuations in the relative position of its elements: at the meso-geographical level this conresponds to the rapid shifts individual cities make between "states" of growth, stagnation, contraction, or changes of rank within the size hierarchy over the medium term; or tenyearly changes in their socioeconomic profiles, which may anticipate, parallel or lag behind a general transformation (Pumain and Saint-Julien, 1978). The fluctuations (or shifts of the element from one state to another) are even more apparent if we adopt the most "microscopic" level of geographical observation, that is, the individuals, households and firms located in the urban centres, on the time scale of one year (residential and professional mobility, creation and demise of companies) or on the time scale of one generation of people being replaced by the next one.

Dynamic models of urban systems have been elaborated in this context whose formalisatio makes explicit some forms of interdependence between the elements of the system, such as the conpetition to attract activities or population. Using dynamic models, the evolution of a set of central places can be simulated from the growth rates and movements of population and employment between the urban centres of a region (White, 1977; Allen an Sanglier, 1979,). Other models have simulated the evolution of city sizes from the migration of individuals between centres (Weidlich and Haag 1988; Sanders, 1992). These models have been related to the macroscopic structure of the urban system, for examples by demonstrating that under certain hypotheses, the distribution of city sizes behaves as an attractor for a synergetic dynamic model of inter-urban migration (Pumain and Haag, 1994).

A general criticism that can be made of dynamic esponsible for the form of the urban system is the competition between its component geographical units to attract and accumulate the product of different resources, and if this competition is made possible by the circulation of information between the units which thus constitute a network, the fact remains that the motor of change is the continuous creation of new products and wealth in the system. Yet the emergence of innovation remains a stumbling-block in dynamic modelling, one that even the most sophisdyated efforts at simulation have failed to resolve ticated efforts

The difficulty experienced by mathematical models to account for creative change for the conmodels to account for creative change, for the conis characteristic of social evolutionary processes, is why models based on a biological analogy have why nocels based al bion those borrowed from physics. The transposition of Lotka-Volterra predphysics. Tols to the study of competition beator-prey 1985; Inos, 1994) is only possible if attention is limited to the observation of relative variation, in limited to he ob the un

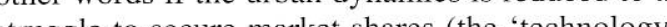
struggle to secure market shares (the 'technology substiciton overlooks, fisst that the liniting factor present in is continally chalenged by hempeticien socies is continually challenged by human societies, and second, that temporarily abanion teritories can always find a different use during a new cycle of innovation, thereby invalidating the idea of an analogy with the tech products.

Here can be seen the limitations of analogies from physics and biology when they are transferred to a theory of urban systems. Although models based on physical systems admit two possible processes of change in the structure of the systems, from bifurcation due to the amplification of an internal fluctuation or the irruption of some external perturbation, they have great difficulty accounting for the crucial phenomenon of innovation. Not only is this to a large extent endogenous to urban systems, but the continuous renewal that it induces means that innovation has a fundamental role in the genesis of the system's structure, through the diversification and complexification of its elements. Consequently it seems inappropriate to consider it simply as a fluctuation or external perturbation. The proces has received considerable attention from economists seeking to replace general equilibrium theory by an evolutionary approach.

Geografiska Annaler · 82 B (2000) · 2
Some authors have also suggested incorporating in the theory not only aspects of physical dynamic but also evolutionary processes based on biologica theories. Allen (1991) has argued that towns and cities belong to the sorts of systems in which new orms and functionalities are created. The appearance of innovation in the systems is not due to some optimisation of their functioning at a given time but results from the practices and "discoveries" and "inventions" of non-average individuals. This is in fact a social interpretation of the notion of diversity from the biological theory of evolution. The models based on this theory require very powerful computers to simulate the endogenous emergence of innovation. However, it is not certain that social innovation, and the learning and collective processes that it implies, can be modelled in quite the same way as a biological phenomenon. Future models will probably have to include cognitive processes, both for their role in the appearance and selection of innovation, and as additional regulators in the evolution. It may then be possible to explain why bifurcations or "chaotic" behaviour are less common in urban systems than in other types of evolutionary systems.

\section{From dynamics to evolutionary theory}

These various analyses do help to identify the characteristics of an authentic evolutionary theory of urban systems (Pumain, 1997). We will not focus here on the substantial transformations in urban form and economy, which in a legitimate way are the basis for most urban research agendas (for instance, Bourne, 1995). Our objective is to concenrate on the few features which can be considered as remaining general and specific properties of urban systens over time. An evolutionary theory has ins to accept that its object is transforned over time, based on its previous forms but acquiring new pes. The theory must set out he general patwhich chese changes and identify their direction, which can then serve as the basis for forecasts. Of lification a theory may be seen as over-simplificationcompared to the complexity of real procperemature to claim that dicate some lines of enquiry which may be of use in its elaboration.

The notion of urban system

A simple definition of an urban network or city sys- 
tem is that of a subset of a settlement system. The latter is made up of all the inhabited localities of the same territory - hamlets, villages, towns and cities - as well as the relations (which can be specified later) that exist between these localities and between them and their surroundings. The fact of being part of the same territory gives a degree of unity to the system's functioning, by providing relatively homogeneous conditions of communication between its elements. The territory is defined here by political and cultural standards, as a contiguou portion of the earth's surface occupied or controlled by a group. The notion of territory also implies a degree of delimitation (its "boundaries" limit the intensity of interactions between localities that belong to different territories) which justifies the identification of a "system". However, it must be noted that the development of urban systems continues regardless of changes in politically-defined territories. Furthermore, when the forms of politico-administrative organization of particular territories have remained stable over long periods they can give rise to specific variants of the general urban system model. Finally, it is clear that to varying degrees cities, particularly those in the upper reaches of the urban hierarchy, are indifferent to territorial boundaries. Since the range of urban relations is strongly correlated to the size of the centre, the reference territory should be proportionate to the level of the hierarchy being considered. The notion of system applied to urban settlements is thus of ultimately limited value and needs to be replaced by a more suitable metaphor. However, it is useful for the purposes of modelling, so we shall continue to the purposes of recelling, so we shall something better is found. The time-scale of evolutionary change is that in
which complexification occurs. Adoption of the evolutionary perspective implies integrating the specific temporalities of cities and the urban system ific temprinitions of these objects. This is only concept of geographical space.

Relative space and geographical entities

Two concepts of space are found in the work of geographers. The more widely used treats space as physical reference which acts as the setting and franework for he andysis of the he The 1979). distibent within it (Beging ward geometric properties, even though it gives only an approximate and distorted representation orth's surface, as, for example, in cartoother concept defises space on the basis of the relations which exist between localities. Because the distibution of these relations is not homogeneous or isotropic or continuous, representation of the "lelatve" space thus produced is not always easy. However, the concept of relative space is essential for understanding the development of what in terms of absolute space are referred to as "spatial structures", that is, detectable and identifiable geographical obects.

Although the theory is still in its infancy, an evolutionary perspective would show how these geographical entities, in the form of villages, areas o jurisdictions, towns, territories, networks, are constructed through the integration over time of relations between localities. Contact and exchange are responsible for the spread and imitation of practic es, for producing personal interaction and share modes of thought and expression. These relation radually create the similarities which underpin the ormation of homogeneous landscapes and regions, as well as the memberships which define the territories and networks. They are at the origin of the accumulations of human and non-human capial which increase the attractivity of some local ties. The interlocking of these constructions at diferent levels is what forms geographical space. A static account of this was given by Philbrick (1957), while a formal analysis has been attempted by Grasland (1994). They have yet to be incorporated into a dynamic theory.

Urban centres construct two spaces

The dynamic models in which cities are formalised as self-organising systems use the representation of an absolute space as providing a setting for centres that are linked by flows (of goods, people and information) to form a system. Progressing from a dynamic theory to an evolutionary theory requires conceptualising a relative space, one that is defined by these relations and flows. It then becomes necessary to distinguish the two levels of observation of the urban phenomenon that are the city and the urban system. First, these two levels of observation of the urban phenomenon correspond to two types of territory, with different relational scales. Second, the changes in this relative space are a source of information ant the origins and history of the urban systems (Pumain, 1995).
At any given time, the urban system, or more generally the settlement system, is responsible for the articulation of territorial entities on different geographical levels, by establishing links between levels of organisation with contrasting space-time dimensions. The settlement system is what makes possible the coexistence of at least two main levels. The first level is that of the village or urban place in its role of territory of daily activity. At differen periods, the composition of internal journeys has varied widely, depending in particular on the degree of specialisation of places for residence, work, commerce, or leisure. The average time devoted to these daily journeys, which has to be added to that of other activities carried out during the day, remains on the whole relatively constant in the order of approximately one hour, and sometimes between one and two hours. The spatial expansion of the territories of daily life is thus severely limited by the time necessary for internal journeys, the speed of which, particularly in the cities, is itself reduced by high density levels (for example, the average speed of road traffic in Paris today is estimated to be $18 \mathrm{~km} / \mathrm{h}$ )

The main functions of the daily territory represented by each cluster in the settlement system are habitat and production (of goods and services). In most cases, however, these two main functions are no longer regulated locally. Their evolution is in the main determined elsewhere, in the nodes of the power networks where decision-making occurs. Some of the power centres in these networks are clearly identified, taking the form of a political or administrative capital, the headquarters of a multinational company. More usually, the forms of the flows of goods, services, labour and ideas which are responsible for the functioning of territories of the higher level of organization, on regional, nationa or even multinational levels, are determined through multiple networks of negotiation, competition and complementarity.

These networks are able to function thanks to the urban system. The forms of circulation which exis in this other level of territorial organization govern the system's spatial structure, as defined by the distance between and size of the urban elements. At this level the distance between the main centre corresponds roughly to the distance that can be traveled in a single day. This length of time is accepted as the average needed for the stages in journey (Reclus, 1895) or for a return trip necessary to conduct fairly frequent negotiations in localities which are not visited every day (Cauvin et al.
1989), within the networks of exchange which can exist between headquarters and subsidiaries, between large companies and their clients, between a capital and its main administrative relays. Although it is not very precise, this measure of a single day does allow a much larger spatial extension for the territories of control and co-ordination than for those of daily life. For any given transport technolgy, not only the length of time determining the spacing of centres in a territory, but also the speed of circulation between them, is in general much greater than that possible within each individual entre (Orfeuil, 1993; Dupuy, 1995).

Definition of a relative space for representing the relational possibilities both within and between urban centres is at the origin of the attention given to fractal geometry for the study of these objects (Arlinghaus, 1985; Frankhauser, 1993; Batty and Longley, 1994). The relational space is strongly organized by density gradients and has a fractal structure. Applied to the description of urban structures, the notion of fractality has the advantage of offering a new reference model to replace that of a homogeneous occupation of space as is used for calculating density. Instead it is the direct expression of the anthropological occupation of space, by incorporating the form generated by the experience of centrality in the description of urban objects. The effect of this is that urban densities (buildings, population, activities, journeys, etc.) do not have a homogeneous spatial distribution but vary systematically depending on their position in relation to one or several centres, following a dilution or fragmentation going from the centre to the periphery. A fractal model is therefore more suitable than the Euclidean model for analysing the properties of urban systems and for identifying their specific features. The early experiments on urban centres and urban networks have found a good fit for the fractal models at the different levels of analysis (Le Bras, 1996). Some authors have also drawn attention to the existence of a clear discontinuity between the fractality of the internal spaces of towns and cities and that between them (François et al., 1995), which would appear to confirm that urban centres induce space-time structuring on two levels. Fractal representation is also an antidote for the shortcomings of the spatial representations of the geometry of urban systems in the Christaller models, which take no account of the differentiation in density which central places create by their presence According to M.-C. Robic (1982), this "distorting" of the spatial models of central places, which was 
given an approximate schematic formalisation by that occurs in one town or city will quickly be copW. Isnard, had been noticed by Reynaud, who pos- ied and adopted in the others. The capacity for tulated a "bending of space" in the vicinity of urban tulated a "be lines of space" in th

Towards a theory of the evolution of settlement Tystems

A conception of the urban system as being responA conception of the ulban systween two levels of sible for the aticulation be seeking an alternative space-time relations inple present structure of to a static forms represents neither a state of equiliburban systems restinum dicted by some constrain rium nor an optimum dictad bone constrain at a particular mones. The spacize urban centres, their size anstant processes whereby uct of more or less cont to modifications in the towns and cities are adnpted peds of circulation, proportions of space by the and an cajusthent of hir forms of social, functional and technical change. Evolutionary theory situras the present structure of the urban system in the context of the general history of settlement systems. The latter is deeply influenced by the process of the urban transition, which is the nane used to describe the changes consequent on the shift from an agramian econing ing mainly local resources, to a manufacturing and service economy, based on long-distance trade. In the countries which had long been settled, as in Europe and Asia, the same sites or settlement nodes have been maintained by the successive economic and political systems that control these territories. The creation of completely new settlements and new towns and cities is an extremely marginal process compared with the overwhelming majority of processes whereby existing centres of habitation are adapted to new functions. In countries which have been more recently settled, a first phase of the change was reflected in a spatial diffusion that followed the advance of settlement and included the establishment of new sites. Once the available territory was fully occupied, however, the forms of evolution became similar to those observed in the countries of long established settlement.

The main dynamic characteristic of urban settlement systems appears to be the competition be tween their elements for the attraction and creation of wealth, by means of exchange, innovation (anticipation) and the adoption (imitation) of innovations. This form of evolution is made possible by the system's high degree of interconnectivity, which enables information to circulate. A change adapting to change is linked to the relative position of urban centres in the system in terms of resources, either linked to the site or accumulated, and the relationship which exists between the rate of adoption of change and previous accumulation (as expressed by the size of urban centre) has been demonstrated by many authors from an examination of the process of hierarchical diffusion of innovation within urban systems (Pred, 1966, 1973). In contrast to the restriction of the volume of population and urban activities that occurs in a biological predator-prey model, inter-urban competition is not zero-sum game and, because it encourages innovation, is continually pushing back the factors that the process of the social division of labour whic expresses this impulse and generates new urban specialisations, and which must consequently be conceptualised as being endogenous to a model. Competition between urban centres to attract distant resources and the product of innovations lead sooner or later (depending on the speed of communications of the moment) to a process of growth an transformation experienced by all the towns an cities in the territory under review. In the context of this generalised quantitative and qualitative expansion, urbanization is interpreted as a diffusion-expansion process affecting all parts of the urban syspem. This process is stochastic, made up of smal the system is continually adapted (or corrected), tion. This same process explains the system's hiertion. This organization as described by Gibrat's model.

The anticipations and imitations performed by the urban agents are non linear processes, however, which can produce bifurcations, that is, modifications to the structure defined by the relative positions of towns in the system. It is for this reason that in periods when systems of settlement are being established, during upheavals in the political organisation of territories, or when particularly selective innovations appear, local mutations (rapid growth, crises, decline) can significantly modify the position of towns in the system. Modelling these nonlinear interactions requires a more complex $\mathrm{dy}-$

The expansion of urban systems appears not to be a contrum process over time. Th the past, he range of urban interactions was for long restricted threaten to limit urban expansion. It is the source of adjustments by which the place of urban centres in with each tending to retain the same relative posinamic than that employed by Gibrat. by the very slow speed of communications, thus preventing towns and cities from developing beyond the limits set by the resources in the accessible territories, which were usually limited in extent.
Historians have established that even in the wealthHistorians have established that even in the wealthiest pre-industrial economies the average urban
population did not exceed 10 per cent of the total population (Bairoch, 1996). The process of urbanization that began with the earliest towns, some two or three thousand years after the appearance of agriculture (Bairoch, 1985), accelerated significantly when the transport revolution opened the way for an extension of the territories and networks that urban centres were able to dominate. The urban transition, which took urbanization levels up to $80 \mathrm{per}$ cent in the industrial nations in little more than a hundred years, could in fact be interpreted as the fairly brutal condensation of a dynamics of interurban competition which although it had started long ago had previously been held in check by slow communications. The transformation of economies from an agrarian to manufacturing and then service basis was accompanied by far-reaching modifications in the distribution of settlement, resulting in a pattern of urban centres that was regularly spaced, and appreciably more hierarchical, contrasted and concentrated than the previous settlement system (see, for example maps of the evolution of the European urban system since the sixteenth century in Bretagnolle et al. (1998))

The relationship between the form of urban systems and the speed of communications can be illustrated, for example, by showing that the spatial structure of urban systems, as well as their degree of hierarchisation, is characterised by variations that reflect the forms of circulation which existed at the time of their creation. For example, the criterion of average distance between towns and the degree of contrast in their size corresponds to a division not between developed and Third World countries but between countries of the Old World and those where settlement is of more recent origin (Moriconi-Ebrard, 1993). As an example, the average space between two urban centres with over 10,000 inhabitants is less than $15 \mathrm{~km}$ in China and in Europe, compred with nearly $50 \mathrm{~km}$ in North America. Similarly an index measuring the size of hierarchicol contrasts between these unbn populations, expressed by the slope of the 'rank-size' distribution, is less the 1 in Europe, over 1.2 in North America, pes developed and developing countries.

In addition, all these systems exhibit a long-term end to more pronounced hierarchical contrasts. This could be explained by the initial advantage consistently obtained by large centres because in(a)

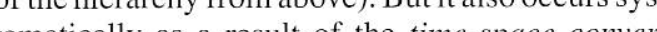
ematically as a result of the time-space convergence, whereby the largest urban centres are able to short-circuit the clientele of the smaller centres that occupy an intermediary position, also inducing "simplification from the bottom" of the urban hierarchy. The most frequently observed deviation from the Gibrat model, a correlation between urban growth and city size, can thus be incorporated into an evolutionary urban theory in which towns an cities are responsible for articulating two types of relational spaces situated on two different time scales and which take into account the historical rend, based on technological progress, to a contraction of geographical space, as measured by journey time.

The construction over time of an increasingly hierarchical settlement system, marked by growing contrasts in the size of its elements, is thus a consequence not of the optimal organisation of circtlation in a territory at a given moment (which disqualifies static explanatory theories such as central place theory and spatial economic equilibrium), but rather of the gradual and historical adaptatio of a system originally created for a particular speed of circulation and which has subsequently been transformed through the effect of faster speeds. In the course of this evolution, the system has also enabled societies to gradually free themselves from local ecological dependence, on the resources offered by their particular site, while reducing the hazards and uncertainties that threaten their survival and development, by considerably enlarging the scope for substitution and complementarity of resources, through the ability to draw on those of increasingly distant sites.

With this conception it becomes possible to combine into a unified concept the organisational duality between, first, the hierarchical organisation of the urban systems that assure the territorial control and servicing, and second, their formation of a network for the exercise of various specialist functions. Unlike in central place theory, we do not have to accept a priori that there are functions which are differentiated by their threshold of appearance or their range, and which order the urban centres into a hierarchic configuration according to their size and the distance between them. The functions are actully oreated in the urbon centres, they are a re- 
sult of a process of social and spatial division of la- have the function of reducing local uncertainty by bour which produces an increasing complexifica- establishing the connectedness of places, achieving tion of functional levels by transforming the places which already exist.

An evolutionary theory has therefore to take into Account what is referred to as complexity. The question remains whether it can be translated into statistical or mathematical models and thus tested? A formalisation of the modes of urban evolutio would have to combine a process of systematise growth like that of Gibrat's model, a competitio between urban centres to attract resources and inbetween over increasingly extended spatial ranges, and a growing complexification of urban activities and social structures consistent with specific historical trends, which are very difficult to model using the classic modelling methods, such as dyusing the clals based on differential equations. namic modes bation Compros sop to a combine in a single model the number of elemenconbine in a sing e tary the evical a vely bacic description of the evolution of an urban system (Bura et al., 1996).

\section{Conclusion}

A fundamental link between the city and communication was established by Remy and Voyé, who defined urbanisation as "a process which integrates spatial mobility into daily life" (1992, p. 7). We have defined the essential function of an urban system in a particular territory as being hat of atticulating two forms which relate sociestes to the vironment, or two modes of production of geographical space, each possessing its own speed of circulation and henceits specific scale gegraphical organization. More than for other social systems, the similarities in the specific organisation of urban systems, their universal structure in varied geographical milieus, economic systems and sociopolitical organisations, cannot be explained without reference to this shared territorial function, and without relating it also to the transcultural but historical processes of the urban transition and the time-space convergence. Urban systems in their present form are the result of these two processes, which have produced a far-reaching transformatio of the practical forms of their main function, of what in terms of spatial organisation has been the constant meaning, which is to articulate the territories of daily life and the networks of authority. U timately, therefore, urban systems can be said establishing the connectedness of laces, achieving size of the two types of territory.

As an alternative to the intractable logical problems of static urban theories, our solution is to conceptualise the urban system as a form of adaptatio to the change that is generated by human societies, an invention whose technical nature is usually no apparent in the collective representations, an which is the product of historical self-organisation processes. The evolutionary specificity of urba systems is to be sought in at least three related processes: in the urban transition, which transforms virtually all urban systems through the expansion, concentration and diversification of a set of settlements whose original function was the agricultural use of aterritory; in the connected, mutually informed and competitive character of the network that human agencies form when densities increase or when urban centres develop (surplus extraction, distribution, exchange); and lastly in the fact that this network is a spatial and historical object, rooted in territory which in anthropological terms does not maintain the same spatial properties over time. The systematic variation in the range of urban relations, the time-space convergence, is an essential process -it is this which differentiates the dynamic of urban systems from that of other dynamic systems and restores to the theory of urban systems its specifically geographical dimension. The evolutionary concept also means taking into account the creative potential of urban centres, given that flows of innovation and the creation of new wealth are the only effective explanations for continued urbanisation.

An evolutionary conception necessitates a funAn eval revision of our representations and methods of analysing change in geographical space. A regulator - perhaps the key regulator - of the size refulator-perhaps the key regurial interactions. It is important that this will be measured in the thes the time-space measwe whill defie the geographical entities that are are graphical mankers or politin the earth-space framelutionary, expanding wincthe work. IT we want to construct an to examine at an ory of these objects, it is neceriect in a geophica interval of time the same object in a gegraphica delimitation which corresponds to the range of its urban place is defined as a portion of the earth- space in which relations are structured by a centre which can be reached in under an hour, the surface that entity covered in 1950 would be roughly double what it was in 1800 , and roughly double the 1950 figure in 1990. Examination of this object, which in the relational space-time would be consistently defined as a 'town' or 'city', is unlikely to reveal the pattern of growth followed by decline in the central area and continuous growth in peripheral districts ever further (physically) from the centre, as proclaimed by the theorists of "counter-urbanisation" (for a critical review see Davies, 1994) and whose forms have been well described by the specialists of peri-urbanisation. On the contrary, the likelihood is that the town or city defined in an evolutionary way will be found to present a sustained trend to growth, compared with its periphery. Similarly, many of the debates over the 'urban exodus' to smaller local spaces could also be interpreted as extensions, in the light of the extension of the spatial range of interactions.

These notions of evolutionary spatial entities can also help geographers to improve their cont bution to certain questions of forecasting: regarding the nature of the post-urban transition, that is about the future evolution of urban systems, the increasing speed of inter-urban circulation and the extension of relational networks leave no doubt about the continuing trend to concentration: in a space-time that is smaller in relation to the spacecontext, an urban network comprising fewer urban places is the transformed equivalent of the earlier urban network. Finally, an evolutionary perspective invites us to take a different view of what are assumed to be the optimal forms in regional planning: the same mechanisms of change may have produced slightly different forms of urban system (for example, French or Romanian centralised network as compared with the networks found in the Rhineland), which constitute so many varieties that are equally viable and not interchangeable with each other, with the capacity of adapting to the changes that are occurring without their structures necessarily becoming more similar. There is no optimal urban system, there are just systems which continue to adapt.

\section{Acknowledgment}

This paper is in part a translation of a paper published in French in L'Espace Géographique (1997. 2, 119-134). We thank Godfrey Rogers for his help in translation.
Denise Pumain, Professor, University Paris I, ReC Genoble, 13 rue du Four Paris,France.E-mail: pumain@parisgeo.cnrs.fr

\section{References}

ALLEN, P. (1978): Dynan
Techniques: $50,15-19$. PUMAIN D). Spatial models of evolutionary systems, in PUMAIN D. (eds): Spatial analysis and popullation $d^{y}$
ics. John Libbey-INED, Congresses and Colloquia 6.

growth in a central place system, Geographical Analysis: growth-272

AMSON, J.C. (1972): Equilibrium models of cities, an axiomatic theory. Environment and Planning A, 4: 429-44.

85): Fractals take a central place. Geografiska Annaler, 67B: 83-88.

Konzentration. Petermans Mitteilungen, 59, 1: 74-76. BAIROCH, P. (1985): De Jericho à Mexico. Paris: Gallimard.

Sach
PUF.
BATTY,

PATY, M. and LONGLEY, P. (1994): Fractal cities. Londo Academic Press.

CKMANN, M.J. and MACPHERSON, J.C. (1970): City size distribution in a central place
Science, 10, 1:25-33 BEGUIN, H. (1988): La région et les lieux centraux, in
C. (ed), Analyse économique spatiale, Paris: PUF.

BEGUIN, H. and THISSE, J. (1979): An axiomatic approach to geographical space. Geographical Analysis, 11, 4: 325-41.
BERRY, B.J.L. (1964): Cities as systems within systems of cities. Papers of the Regional Science Association.
BERRY, B. (1967): The Geography of Markets Centers and Retail Distributition. Englewood Cliffs: Prentice-Hall. BERTUGLIA, C.S. and LA BELLA, A. (eds) (1991): I sistemi urbani. Milano: Franco Angeli (2 vol.).
BIRD, J. (1977): Centrality and cities, London: Routledge \& Kegan Paul.

UURNE, L.S. (1995): Urban systems in an era of global restrucluring: expanding the research agenda, in PALOMÄKI, M.
and KARANARATNE, J.A. (eds): Urban Development and Urban Life, Acta Wasaensia, 45: 15-39. BRETAGNOLLE, A., PUMAIN, D. and ROZENBLAT, C.,
(1998): Space-time contraction and the dynamics of urban systems Cybergeo, 61: $12 \mathrm{p}$.

F. MATHIAN, H. PUMAIN, D. and SANDERS, L. (1996): Multi-agents systems and the dynam-
ics of settlement systems, Geographical Analysis: 161-78. MAGNI, R. (1990): Strutture urbane gerarchiche e reticolari: verso una teorizzazione, in CURTI, F. and DIAPPI, L. (eds): Angeli.

Angeli.
CAMAGNI, R. (1993): Economia urbana. Milan: Franco Angeli.
CASTELLS, M. (1990): The Informational City. Oxford: BlackCASTEL
well.
C.P.

well.
CATTN, M. (1994): Les économies d'agglomération, in AURAY, (1994): Encyclopédie d'Economie spatiale. Paris: Economica.
AUVIN, C. REYMOND H. and SCHAUB, R. (1989): Accessibilité, temps de séjour et hiérarchie urbaine, Sistemi Urbani 
CHEVALIER, M. (1832): "Système de la Méditerranée", Le ORFEUIL, J.P. (1993): Je suis l'automobile. Paris: Editions de Globe, 12 February.
CHRISTALLER, W. (1933): Die Zentralen Orte in Süddeutschland: eine Ökonomisch-Geographische Untersuchung Über
die Gesetz Massigkeit der Verbreitung und Entwicklung der Siedlungen mit Stöditsschen Funktionen, Iena: Fischer Verlag: Central places in Southern Germany, Englewood Cign
Prentice Hall, NJ.)

CLAVAL, P. (1982): La logique des villes. Paris: LITEC.

CURRY, L. (1964): The random spatial economy: an exploration in settlement theory. Annals of the Association of American Geographers: 138-46.

, des villes en réseau. Paris: La Doc-

DAVIES, W.K.D. (1994): Counter-urbanization in perspective, in BRAUN, G.O. (ed): Managing and Marketing of Urban Development and Unan Life. Berlin: Diench Rer-

Dawson, J.A. (1969): Some early theories of settlement locatio and size, Journal of the Town Planning Institute, 55: 444-448. DELUZ, C. (1989): Villes et organisation de l'espace: la Chine de
Marco Polo, in: Villes, bonnes villes, cités et capitales. MéMarco Polo, in: Villes, bonnes villes, cités et capitales. Me-
langes offerts a Bernard Chevalier. Tours. DEMATTEIS, G. (1985): Verso strutture urbane reticolari, in BIANCHI, G. and MAGNANI, I. (eds): Sviluppo regionale: teorie, metodi, problemi. Milan: Franco Angeli. DENDRINOS, D.and MULLALY, H. (1985): Urban evolution. Oxford: Oxford University Press

es de l'automobile. Paris: An-

thropos, coll. Villes.
ERANCOIS, N.. FRANKHAUSER, P. and PUMAIN, D. (1995); Villes, densité et fractalité, Annales de la Recherche Urbaine, 67: 54-63.

FRANKHAUSER, P. (1993): La fractalité des structures urbaines. Paris: Anthropos.

size. Cambridge: Cambridge University Press.

FUIITA, M., KRUGMAN, P. AND MORI, T. (1994): On the evolution of hierarchical urban systems. Niagara Falls: No GEDDES, P. (1915): Cities in evolution. An introduction to Town planning movement and to the study of civics. London: William and Norgate.

omiques. Paris: Sirey. tor ries and coexistence. Bâle: Peter Lang, 425-40.

GUÉRIN-PACE, F. (1993): Deux siècles de croissance urbaine. Paris: Anthropos.
HAKEN, H. (1977): S

PHILBRICK, A.K. (1957): Principles of areal functional organisation in regional human geography. Economic Geography. $299-336$.

H. (1925): Les villes du Moyen-Age. Paris: PUF. Cospatial dynamics of US industrial grow mation flows, Lund Studies in Geography, Series B: 38

Hutchis (n) PUMAIN, D. (1982): La dynamique des villes. Paris: Economica. settlement systems. Flux, 21: 11-20

Po villes, $L^{\prime} E$ pace Géographique, 2: 119-34.

(1978): Les dimensions du

changement trbaint. Paris: CNRS.
UMAIN, D. SANDERS, L. and SAINT-JULIEN T. (1989),

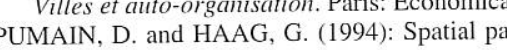

(1) Evolution of Natural Structures, 3rd International Symposium of the Sonderforschungbereich 230, Universität Stuttgart, 4-7 october, Natürliche Konstruktionen, Mitteilungen des SrB $230, \mathrm{He}, \mathrm{N}$ : 243-52. DERYCKE PH. HUUIOT JM and PUMAIN, D. (eds) Penser la ville, Paris: Anthropos. UMAIN D. and MORICONI-EBRARD, F. (1997): City size distribution and metropolisation. Geojournal, 43, 4: 307-14
RACINE, J.B. (1994): La ville entre Dieu et les hommes. Paris RACINE, J.B. (1994): La ville entre Diel et les hom
Anthropos. Anthropos.
RECLUS, E. (1895 Review, 67, 2: 246-64. REINER, T.A. and PARR, J.B. (1980): A note on the dimensions of a national settlement pattern, Urban Studies, 17: 223-30. Paris: L'Harmattan. REYMOND, H. (1981): Une problématique théorique, in: Isnard, H. Racine, J.B. and Reymond, H., Problématiques de la géographie. Paris:P.U.F.

REYNAUD, J. (1841): Villes, in Encyclopédie nouvelle. Paris: ROBIC, M-C. (1982): Cent ans avant Christaller, une théorie des lieux centraux, L'Espace Géographique, 1: 5-12. ROBIC, M.-C. (1984): Jean Reynaud (1806-1863), in PINCHEMEL P., ROBIC M.-C. and TISSIER J.-L, 1984, Deux sièdes Travaux historiques et scientifiques. er.
JULLARD, E. (1972): Espace et temps dans l'évolution des cadres régionaux $x$, in Etudes de géographie tropicale offertes à $\mathrm{P}$. Gourou. Paris: Mouton, 29-43.

Let l'Europe. Paris: La DocLEPETTT, B. (1988): Les

LETET, B. a.s AMMAiN, D. (eds) (199). Temporalités utLÖSCH. A. (1940): Die Rëumliche Ordnung der Wirtschaft. MEES, A.I. (1975): The revival of cities in medieval Europe, $R e-$ gional Science and Urban Economics, 5: 403-25, Lurbanisation du monde Jepuis 1950. Paris: Anthropos.
Methuen.
ROUSSEAU, M.P. and Prudhomme, R. (1993): Les bénéfices de

ropén vue d'Economie Régionale et Urbaine, 4: 661-78.

SANDERS, L. (1992): Système de villes et synergétique. Paris: Anthropos.
SASEN, S.
(19)

(1991): The Global city: New York, London, Tokyo. Princeton, NJ: Princeton University Press.
SUAREZ-VILLA. L. (1988): Metropolitan Evolution, Sectoral Economic Change, and the City-Size Distribution. Urban Studies, 25, 1: $1-20$

Cities and Information Flows, Lund Studies in Geography, Serie B, 38. la concentration parisiemne. Paris: IAURIF
ULLMAN, E.L. (1941): A theory of location for cities. American Journal of Sociology. VLORA, N.R. (1979): Citttà et territorio. Bologne: Pàtron. VRIES, J. de (1984): European Urbanization 1500-1800. Lon-

don. Met, W. and HAAG, G. (1988), Interregional Migration. Berlin: Springer Verlag.
WHITE, R.W. (1977): Dynamic central place theory. Geographi$10: 226-43$.

WonPF, G.K. (1949), Human Behaviour and the Principle of Least
Effort Cambridge: Addison Wesley 